\title{
KARAKTERISTIK DAN PROFIL ASAM LEMAK KOMBINASI MINYAK IKAN PATIN DAN MINYAK HATI IKAN HIU
}

\author{
M Lamudin Nor ${ }^{1}$, Andarini Diharmi ${ }^{2 \star}$, Rahman Karnila ${ }^{2}$ \\ ${ }^{1}$ Magister Ilmu Kelautan Pascasarjana Universitas Riau \\ ${ }^{2}$ Departemen Teknologi Hasil Perairan, Fakultas Perikanan dan Kelautan Universitas Riau \\ Kampus Binawidya km 12,5 Sp. Baru Panam, Tampan, Pekanbaru Riau
}

Telp. 0761 (63274)

Diterima: 21 Desember 2020/Disetujui: 27 April 2021

*Korespondensi: rini_abrar@yahoo.com

Cara sitasi: Nor ML, Diharmi A, Karnila R. 2021. Karakteristik dan profil asam lemak kombinasi minyak ikan patin dan minyak hati ikan hiu. Jurnal Pengolahan Hasil Perikanan Indonesia. 24(1): 122-130.

\begin{abstract}
Abstrak
Minyak ikan patin mengandung kadar asam lemak omega-9, tetapi rendah asam lemak omega 3 Minyak hati ikan hiu memiliki kandungan asam lemak omega 3 relatif tinggi. Penelitian ini bertujuan untuk menentukan karakteristik dan sifat kimia minyak ikan patin dan profil asam lemak kombinasi minyak ikan patin dengan hati kan hiu. Metode penelitian eksperimen dengan melakukan ekstraksi lemak perut ikan patin secara dry rendering dihasilkan minyak kasar dan dimurnikan. Minyak ikan patin murni dilakukan pencampuran dengan minyak hati ikan hiu. dengan perbandingan 1:1, 2:1 dan 2:1. Parameter analisis terdiri atas karakteristik kimia (bilangan asam lemak bebas (ALB),bilangan asam, peroksida, iod, p-anisidin, penyabunan, total oksida/totox), dan profil asam lemak. Hasil penelitian menunjukkan bahwa kombinasi minyak patin dan hati ikan hiu dihasilkan karakteristik kimia terdiri atas asam lemak bebas sebesar 1,59-2,19\%, bilangan asam 2,86-3,00 mg KOH/g, peroksida 15,50-18,32 meq/kg, iod 63,46-84,42 gI2/100g), p-anisidin 21,53-24,16, penyabunan 142,21-162,28 mg KOH/g dan TOTOX 53,33-69,43. Hasil analisis komposisi asam lemak jenuh (saturated fatty acid/SAFA) dihasilkan asam palmitat tertinggi, asam lemak tak jenuh tunggal (mono unsaturated fatty acid/MUFA) asam oleat, dan asam lemak tak jenuh ganda (polyunsaturated fatty acid/PUFA) asam linoleat. Hasil analisis karakteristik kimia kombinasi minyak ikan patin dan hati ikan hiu sesuai dengan standar IFOMA. Kombinasi minyak hati ikan hiu dan ikan patin dengan perbandingan (2:1) dihasilkan kandungan omega 3 dan omega 6 sebesar 2,59 \% dan 29,75\%.
\end{abstract}

Kata kunci: asam lemak, karakteristik kimia, omega 3, omega 6

\section{Characteristics and Fatty Acid Profile of Catfish and Shark Liver Oil Mixture}

\begin{abstract}
Catfish oil is rich in omega-9 fatty acids but low in omega-3 fatty acids. Meanwhile, shark liver oil has a relatively high omega 3 fatty acids content. This study was aimed to determine the characteristics and chemical properties of catfish oil and the fatty acid profile of the catfish oil and shark liver mixture. TBbelly fat of catfish was extracted by dry rendering resulting crude and purified oil. The refined catfish oil ismixed with shark liver oil with a ratio of 1: 1,2:1 and 2: 1 . The analysis parameters consisted of chemical characteristics (free fatty acid, acid value, peroxide, iodine, p-anisidine, saponification, total oxidation/TOTOX), and fatty acid profile. The results showed that the combination of catfish oil and shark liver produced free fatty acids ranging from 1.59-2.19\%, acid number $2.86-3.00 \mathrm{mg} \mathrm{KOH} / \mathrm{g}$ peroxide value15.50-18.32 meq $/ \mathrm{kg}$, iodine number 63.46- $84.42 \mathrm{gI} / 100 \mathrm{~g}$ ), p-anisidin value 21.53-24.16, saponification 142.21-162,28 $\mathrm{mg} \mathrm{KOH} / \mathrm{g}$, and TOTOX 53.33-69.43. Palmitic acid, oleic acid, and linoleic acid were the most dominant saturated, monounsaturated and polyunsaturated fatty acid, respectively. The chemical properties meet the IFOMA's standards. The combination of shark liver oil and catfish with a ratio $(2: 1)$ resulted in the highest content of omega-3 (0.65\%) and omega-6 (29.75\%).
\end{abstract}

Keywords: chemical characteristic, fatty acid, omega-3, omega-6 


\section{LATAR BELAKANG}

Ikan patin umumnya dikonsumsi dalam bentuk segar atau diolah menjadi filet dan ikan asap. Proses pengolahan ikan patin asap menghasilkan limbah berupa hasil samping terdiri atas isi perut di antaranya lemak perut. Hasil samping tersebut dapat dimanfaatkan sebagai bahan baku tepung dan minyak. Beberapa penelitian menunjukkan lemak perut ikan patin dapat dimanfaatkan sebagai bahan baku minyak. Minyak ikan hasil ekstraksi dari sisa pengolahan filet ikan patin mengandung asam palmitat $33,95 \%$, oleat $35,85 \%$, dan PUFA sebanyak $12,35 \%$, berupa asam lemak linoleat, linolenat, EPA, dan DHA (Hastarini 2012). Rodiah et al. (2013) telah melakukan ekstraksi isi perut ikan patin dengan metode dry rendering selama 8 jam dihasilkan minyak dengan karakteristik mutu asam lemak bebas $(1,67 \pm 0,38 \%)$ dan bilangan peroksida $(4,26 \pm 0,13)$. Karakteristik mutu minyak yang dihasilkan tersebut belum memenuhi International Fish Oil Standard (IFOS 2014). Ayu et al. (2019), menyatakan bahwa minyak ikan patin memiliki komposisi asam lemak dominan asam palmitat, stearat, dan miristat, sedangkan asam lemak tidak jenuh oleat, linoleat, dan linolenat. perbandingan asam lemak n-3:n-6:n-9 dalam minyak ikan patin 1:10:20. Hasil penelitian tersebut menunjukkan bahwa minyak ikan patin dapat dimanfaatkan sebagai salah satu sumber pangan fungsional.

Minyak ikan patin yang kaya kandungan asam lemak tak jenuh terutama omega 6 dan omega 9. Omega 6 dan 9 merupakan asam lemak tak jenuh dapat dimanfaatkan menurunkan kolesterol darah atau low density liprotein (LDL). Hal ini terbukti dari beberapa hasil penelitian bahwa konsumsi PUFA mampu menurunkan potensi risiko penyakit kardiovaskular termasuk kolesterol plasma, triasilgliserol (TAG), inflammatory cytokines, chemoattarctants, cell adhesion molecules, eikosanoid, tekanan darah, dan menurunkan kematian pada penderita penyakit kardiovaskular (Bucher et al. 2002; Mozaffarian dan Rimm 2006). Selain menurunkan resiko penyakit jantung koroner minyak ikan juga dapat mencegah peradangan, efek hypotriglyceridemic, alergi, hipertensi, arthritis, gangguan autoimun, dan kanker (Von Schack 2003). Hasil penelitian Orban et al. (2008) dan Thammapat et al. (2010) menunjukkan minyak ikan patin memiliki kandungan asam lemak omega 6 dan 9 relatif tinggi sedangkan omega-3 tidak ada. Asam lemak omega 6 dan 9 memiliki peranan yang berbeda. Haris et al. (2009) menyatakan bahwa omega 6 berperan dalam penghambatan trombosis, merawat membran sel, dan menjaga keseimbangan kolesterol.

Omega 3 banyak terdapat pada ikan laut salah satunya adalah ikan hiu (Centrophorus atromarginatus). Hati ikan hiu merupakan salah satu sumber bahan baku pembuatan minyak ikan yang kaya akan omega 3. Hasil penelitian Suseno et al. (2010) menyatakan bahwa minyak ikan hiu kaya asam lemak omega 3. Kandungan asam lemak tak jenuh/ poly unsaturated fatty acid (PUFA) 19,11\%. Nilai EPA dan DHA pada minyak hati ikan hiu adalah 1,50 dan 14,35\% (Suseno (2010).

Keseimbangan rasio antara omega 9, 6, dan 3 diperlukan untuk keseimbangan fisiologi pada manusia (Jacobsen 2004). Keseimbangan konsumsi omega 9, 6 dan 3 dapat dicapai dengan kombinasi minyak ikan patin dan hati ikan hiu botol.

Hasil penelitian sebelumnya menunjukkan bahwa minyak ikan patin rendah kandungan omega-3. Oleh karena itu untuk meningkatkan kandungan omega 3 perlu dilakukan penambahan minyak hati ikan hiu. Kombinasi penambahan minyak ikan patin dan ikan hiu masih jarang dilakukan, sehingga perlu dilakukan penelitian tentang karakteristik dan profil kombinasi minyak ikan patin dan hati ikan hiu. Kombinsi penambahan minyak ikan patin dan ikan hiu diharapkan dapat meningkatkan kandungan omega 3 dan omega 6. Penelitian ini bertujuan untuk menentukan karakteristik kimia (asam lemak bebas, bilangan asam, peroksida, iod, 
p-anisidin, penyabunan, total oksidasi, dan profil asam lemak).

\section{MATERI DAN METODE Bahan dan Alat}

Bahan utama terdiri atas sisa pengolahan ikan patin berupa lemak perut (fat abdomen) dan minyak hati ikan hiu komersial tanpa merek dibeli dari Toko Herbal Surakarta. Bahan kimia untuk analisis adalah standar p-anisidin (Sigma Chem. Co., St Louis, MO), toluena (Merck), bipiridin (merck), etanol (merck), $\mathrm{FeCl}_{3} \cdot 6 \mathrm{H}_{2} \mathrm{O}$ (merck), asam asetat glasial (merck), kloroform (merck), KI jenuh (merck), $\mathrm{Na}_{2} \mathrm{SO}_{3}$ (merck), isooktan (merck), n-heksana (merck), aluminium foil, metilen klorida, dan gas nitrogen.

Peralatan yang digunakan terdiri atas alumunium foil, stop watch, timbangan analitik (Boeco, Jerman), buret, alat-alat gelas, kompor listrik, sentrifugasi, heating drying oven, stirrer, waterbath, spektrofotometer UV-Vis 2500 (Labo Med), kromatografi gas, (Shimadzu, Jepang), pipet mikro, dan peralatan lainnya.

\section{Metode Penelitian}

Minyak lemak perut ikan patin diekstrak secara dry rendering, dan dilanjutkan dengan pemurnian minyak. Minyak ikan patin murni dilakukan pencampuran dengan kombinasi perlakuan A1 (1:1) minyak hati ikan hiu 1 bagian dan ikan patin I bagian, A2 (1:2), 1 bagian ikan hiu, 2 bagian patin, dan A3 (2 bagian minyak hati hiu: 1 bagian minyak ikan patin). Kombinasi ketiga perlakuan dilakukan analisis parameter oksidasi primer dan sekunder serta komposisi asam lemak

\section{Preparasi bahan baku dan ekstraksi minyak ikan patin}

Bahan baku dari hasil limbah pengolahan ikan patin dicuci dengan air mengalir. Ekstraksi minyak mengacu pada Damongilala (2008). Ekstraksi dilakukan dengan metode dry rendering. Lemak perut ikan patin dihomogenkan menggunakan blender, dan dimasukkan ke dalam oven yang menggunakan sistem listrik lewat elemen pengatur suhu. Lemak ikan patin dipanaskan dengan oven listrik pada suhu $70{ }^{\circ} \mathrm{C}$ selama 8 jam. Minyak ditampung dalam wadah dan disentrifugasi untuk memisahkan kotorannya.

\section{Pemurnian minyak ikan patin kasar (modifikasi Rodiah et al. 2016)}

Minyak ikan patin kasar dimasukkan ke dalam wadah alat pemurnian yang disusun pada saringan vakum, dan dipanaskan sampai pada suhu mencapai $60^{\circ} \mathrm{C}$ dan ditambahkan dengan adsorben bentonic dan arang aktif dengan jumlah $1 \%$ dari bobot minyak yang dimurnikan. Minyak ikan patin dipanaskan mencapai suhu $70^{\circ} \mathrm{C}$, selama 30 menit. Minyak ikan patin murni dimasukan ke dalam botol gelap dan disimpan pada suhu $-18^{\circ} \mathrm{C}$ sebelum dianalisis.

\section{Kombinasi campuran minyak ikan dan karakterisasi sifat fisiko kimia kombinasi minyak ikan patin dan minyak ikan hiu}

Kombinasi perlakuan A1, A2 dan A3 dilakukan analisis sifat kimia (bilangan asam lemak bebas, bilangan asam, peroksida, iod, bilangan penyabunan, $\mathrm{p}$-anisidin, total oksidasi/TOTOX, dan profil asam lemak).

\section{Asam lemak bebas (FFA) (AOCS 1998 No. Metode Ca 5a-40)}

Sampel minyak ditimbang sebanyak 10 g dan dimasukan kedalam Erlenmeyer 200 $\mathrm{mL}$ ditambahkan dengan $25 \mathrm{~mL}$ alkohol 95\% dan dipanaskan 10 menit, dan ditambahkan dengan indikator PP $2 \mathrm{~mL}$, dititrasi dengan $\mathrm{KOH}$ 0,1 N sampai terjadi perubahan warna merah muda dapat bertahan selama 10 detik nilai FFA dihitung menggunakan rumus sebagai berikut:

Keterangan:

$$
\% \mathrm{FFA}=\frac{a \times n \times m}{\text { Bobot sampel }(g)}
$$

a: Jumlah $\mathrm{mL} \mathrm{KOH}$ yang digunakan n: konsentrasi larutan $\mathrm{KOH}$ (normalitas ) g: bobot sampel (g) $\mathrm{m}$ : bobot molekul asam lemak dominan (asam oleat: 282,5 ) 
Bilangan asam (AV) (AOCS 1998 No. Ca 5a-40)

Sampel minyak ikan kemudian dititrasi dengan $\mathrm{KOH}$, berdasarkan prinsip untuk menetralkan $1 \mathrm{~g}$ lemak dibutuhkan mg total $\mathrm{KOH}$ yang digunakan. Persamaan untuk menghitung bilangan keasaman adalah:

Keterangan:

$$
\text { Bilangan asam }=\frac{v \times n \times k}{g}
$$

n: Konsentrasi $\mathrm{KOH}(\mathrm{mg} / \mathrm{mL})$

$\mathrm{v}$ : Volume $\mathrm{KOH}$ untuk titrasi $(\mathrm{mL})$

k: Bobot molekul KOH (56.1)

g: Bobot sampel minyak (g)

\section{Bilangan peroksida (PV) (AOCS 1995)}

Minyak sebanyak $5 \mathrm{~g}$ dimasukkan ke dalam erlenmeyer $250 \mathrm{~mL}$, ditambahkan $30 \mathrm{~mL}$ asam asetat dan kloroform dengan perbandingan 3:2, dan ditambahkan $0,5 \mathrm{~mL}$ larutan potasium iodida (KI), kocok larutan hingga tercampur, masukan akuades sebanyak $30 \mathrm{~mL}$. Titrasi dengan sodium tiosulfat $\left(\mathrm{Na}_{2} \mathrm{~S}_{2} \mathrm{O}_{3}\right) \quad 0,01 \mathrm{~N}$ sampai larutan mengalami perubahan warna menjadi kuning, kemudian ditambahkan dengan larutan kanji 1\% sebanyak $0,5 \mathrm{~mL}$ sampai terjadi perubahan warna menjadi biru. Larutan dititasi dan dikocok sampai terjadi perubahan warna biru menjadi biru muda. Bilangan peroksida dihitung dengan menggunakan persamaan sebagai berikut:

Nilai Peroksida $=\frac{S \times M \times 1000}{\text { Berat Sampel }(g)}$

Keterangan:

S: Jumlah sodium tiosulfat $(\mathrm{mL})$

M: Konsentrasi sodium tiosulfat $(0,01 \mathrm{~N})$

\section{P-anisidin/bilangan anisidin (Watson 1994)}

(AV)

Analisis p-anisidin tahap awal dilakukan pembuatan larutan uji 1 yang terdiri atas $1 \mathrm{~g}$ minyak ke dalam labu dilarutkan di dalam 25 $\mathrm{mL}$ trimetilpentana. Selanjutnya larutan uji 2 dibuta dengan mengambil $5 \mathrm{ml}$ larutan uji 1 dan ditambahkan $1 \mathrm{~mL}$ larutan $\mathrm{p}$-anisidin (2,5 g/L) sambil dikocok dan disimpan pada ruang tanpa cahaya. Selanjutnya dibuat larutan referensi dengan cara mengambil 5 $\mathrm{mL}$ larutan trimetilpentana dan ditambahkan $1 \mathrm{~mL}$ larutan $\mathrm{p}$-anisidin $(2,5 \mathrm{~g} / \mathrm{L})$ lalu dikocok dan di simpan pada tempat tanpa cahaya. Kemudian diukur absorbansinya, dengan panjang gelombang $350 \mathrm{~nm}$. Penentuan nilai anisidin adalah:

Nilai anisidin $=\frac{25 \mathrm{x}(1,2 \mathrm{~A} 1-\mathrm{A} 2)}{\mathrm{m}}$

Keterangan:

A1 = Absorbansi larutan uji 1

A2 = Absorbansi larutan uji 2

$\mathrm{m}=$ Bobot sampel pada larutan uji 1

Total oksidasi (TOTOX) (Perrin 1996)

Nilai total oksidasi dihasilkan dari hasil analisis bilangan peroksida dan p-anisidin, dihitung dengan persamaan sebagai berikut:

$$
\text { Total oksidasi }=2 \mathrm{PV}+\mathrm{p}-\mathrm{AV}
$$

Keterangan:

2PV : nilai peroksida di $\mathrm{x} 2$

$\mathrm{p}-\mathrm{AV}$ : nilai $\mathrm{p}$ anisidin

\section{Analisis komposisi asam lemak (AOAC 2005 No. metode 969.33)}

Prinsip analisis asam lemak dengan cara menjadikan turunannya, agar terdeteksi di alat kromotografi maka harus diubah menjadi metil ester. Hasil analisis dihasilkan beberapa puncak dan dibandingkan dengan standar yang ada melalui waktu dan retensi tertentu yang sesuai karakteristik setiap asam lemak.

\section{Analisis Data}

Data dianalisis berdasarkan persamaan dan perhitungan kemudian dibahas secara deskriptif dan komprehensif dengan literatur yang sesuai. Data disajikan dalam bentuk tabel, skema, gambar dan ditarik kesimpulan.

\section{HASIL DAN PEMBAHASAN \\ Karakteristik Sifat Kimia Kombinasi Campuran Minyak Ikan Patin Dan Minyak Hati Ikan Hiu}

Hasil analisis karakteristik kimia campuran minyak ikan patin dan hati ikan hiu terdiri atas 3 perlakuan yang pertama A1(1:1) yang kedua A2(1:2) yang ketiga A3(2:1) disajikan pada Table 1 .

Kadar asam lemak bebas yang terdapat pada perlakuan A1 adalah 1,59\%, A2 2,19\%, A3 1,51\% dengan nilai bilangan asam A1 
Table 1 Chemical characteristic of oil from catfish and shark liver

\begin{tabular}{lrrrrr}
\hline \multicolumn{1}{c}{ Chemical Characteristic } & \multicolumn{1}{c}{$\mathrm{A} 1$} & \multicolumn{1}{c}{$\mathrm{A} 2$} & \multicolumn{1}{c}{ A3 } & \multicolumn{1}{c}{ IFOS } & \multicolumn{1}{c}{ IFOMA } \\
\hline Free fatty acis/FFA (\%) & $1.59 \pm 0.04$ & $2.19 \pm 0.04$ & $1.51 \pm 0.05$ & $\leq 1.50$ & $\leq 1-7$ \\
Acid number (mg KOH/g) & $2.86 \pm 0.32$ & $4.36 \pm 0.10$ & $3.00 \pm 0.12$ & $\leq 3.00$ & - \\
Peroxide value/pV (meq/kg) & $15.50 \pm 0.95$ & $15.90 \pm 0.69$ & $18.32 \pm 0.45$ & $\leq 3.75$ & $3-20$ \\
Iodine Number gI2/100g & $83.97 \pm 0.83$ & $63.46 \pm 0.79$ & $84.82 \pm 0.90$ & $\leq 15.00$ & $4-60$ \\
p-Anisidine/pAV & $24.16 \pm 0.06$ & $21.53 \pm 0.08$ & $22.79 \pm 0.13$ & $\leq 20.00$ & - \\
Saponification number & $158.54 \pm 8.16$ & $142.21 \pm 8.18$ & $162.28 \pm 9.78$ & & - \\
(mgKOH/g) & & & & & \\
Oxidation total (TOTOX) & 55.16 & 53.33 & 59.43 & $\leq 26.00$ & $10-60$ \\
\hline
\end{tabular}

Note: ratio between catfish oil and shark liver oil A1 (1:1), A2 (1:2) dan A3 (2:1)

2,86 mg KOH/g, A2 4,36 mg KOH/g, A3 3,00 mg KOH/g. Hasil analisis kadar ALB pada perlakuan A1 dan A3 masih terbilang cukup mendekati International Fish Oil Standar (IFOS) kecuali pada A3. Bilangan peroksida menurut International Association of Fish Meal Manufacturers (IFOMA) menetapkan 3-20 meq/kg minyak dan kadar asam lemak bebas dibawah 7\% (Bimbo 1998). Standar Farmakope Indonesia menetapkan bilangan peroksida minyak ikan mutu pangan (food grade) maksimal $5 \mathrm{meq} / \mathrm{kg}$ (Abdillah 2008). Bilangan peroksida A1 15,50 meq/kg, A2 15,90 meq $/ \mathrm{kg}$, A3 18,32 meq $/ \mathrm{kg}$. Bilangan peroksida pada ketiga perlakuan belum memenuhi standar IFOS meskipun telah memenuhi standar IFOMA. Tingginya kadar bilangan peroksida pada ketiga perlakuan diduga karena oksidasi lemak oleh oksigen secara spontan diakibatkan pada proses ekstraksi, pemurnian dengan suhu relatif tinggi, dan kondisi penyimpanan. Hal ini sesuai dengan penyataan Kilcast dan Subramaniam (2011) bahwa kecepatan proses oksidasi lemak dipengaruhi oleh suhu dan kondisi penyimpanan.

Bilangan iod kombinasi ikan patin dengan minyak hati ikan hiu pada perlakuan A1 $\left(83,97 \quad \mathrm{gI}_{2} / 100 \mathrm{~g}\right), \quad$ A2 $\quad\left(63,46 \mathrm{gI}_{2} / 100 \mathrm{~g}\right)$ dan A3 (84,82 $\left.\mathrm{gI}_{2} / 100 \mathrm{~g}\right)$. Bilangan iod menunjukkan bahwa adanya asam lemak tak jenuh sebagai penyusun dari minyak hati hiu dan patin. Menurut Kataren (2005) minyak dengan kandungan asam lemak jenuh tinggi maka mengikat iod dalam jumlah banyak dan membentuk senyawa jenuh. Tingginya bilangan iod yang diikat oleh asam lemak menunjukkan banyaknya ikatan rangkap yang terdapat dalam minyak. Bilangan iod pada penelitian ini yang tertinggi pada perlakuan A3, menunjukkan bahwa pada minyak tersebut tinggi kandungan asam lemak tak jenuh. Hal ini sesuai dengan penelitian Ayu et al (2019) minyak ikan patin murni dari lemak perut memiliki asam lemak tak jenuh yang tinggi dengan kandungan bilangan iodnya sebesar 99,60 $\mathrm{gI}_{2} / 100 \mathrm{~g}$. Bilangan iod pada minyak ikan patin murni dari lemak perut diekstraksi dengan metode dry rendering memiliki bilangan iod sebesar $185,86 \mathrm{gI}_{2} / 100 \mathrm{~g}$ (Rodiah et al. 2016). Beberapa hasil penelitian menunjukkan perbedaan bilangan iod pada minyak ikan hal ini diduga karena proses ekstraksi dan pemurnian yang digunakan. Hal ini sesuai dengan pernyataan Khoddami et al. (2012) bahwa perbedaan waktu penangkapan atau pemanenan, jenis kelamin, tingkat kematangan gonad, perbedaan spesies, dan jenis sampel berpengaruh terhadap perbedaan bilangan iodin dalam minyak ikan.

Bilangan penyabunan menunjukkan bahwa besar kecilnya molekul asam lemak yang terdapat pada minyak minyak ikan patin dan hati ikan hiu. Hasil analisis minyak kombinasi dengan perlakuan A1, A2, dan A3 dihasilkan bilangan penyabunan berturutturut $158,66142,21$, dan $162,28 \mathrm{mg} / \mathrm{KOH}$. Minyak tersusun dari asam lemak rantai karbon pendek memiliki bobot molekul relatif kecil sehingga bilangan penyabunannya relatif besar dan sebaliknya. Panjang dan pendeknya rantai asam-asam lemak yang dimiliki oleh 
minyak hati ikan hiu ini sangat tergantung ukuran lemak yang dimiliki dari masingmasing molekul lemak ikan tersebut (Ahmad 2014).

Hasil analisis bilangan p-anisidin pada setiap perlakuan berturut-turut A1 24,16 $\mathrm{meq} / \mathrm{kg}$, A2 21,53 meq/kg, dan A3 22,79 meq/kg. Bilangan p-anisidin perlakuan A2 mendekati nilai standar IFOMA (1998) yaitu 4-60 dan belum memenuhi standar IFOS. Reaksi yang terjadi antara senyawa aldehida dengan pereaksi para-anisidin pada pelarut asam asetat akan menghasilkan warna kuning, nilai absorbansinya diukur pada panjang gelombang $350 \mathrm{~nm}$ (Kusharto et al. 2015).

Kadar TOTOX yang terdapat pada perlakuan A1 55,16 meq/kg, A2 53,33 meq/ $\mathrm{kg}$ dan A3 59,43 meq/kg. Hasil analisis menunjukkan bahwa kadar TOTOX ketiga perlakuan belum memenuhi standar IFOS dan memenuhi standar IFOMA. Nilai total oksidasi (TOTOX) merupakan penjumlahan dari hasil oksidasi primer dan sekunder yaitu 2 kali bilangan peroksida ditambah bilangan anisidin (Estiasih 2009).

\section{Profil asam lemak kombinasi minyak ikan patin dan hati ikan hiu}

Hasil analisis komposisi asam lemak campuran minyak ikan patin dan minyak hati ikan hiu disajikan pada Table 2. Hasil analisis profil asam lemak menunjukkan bahwa kombinasi minyak ikan patin dan hati ikan hiu dihasilkan profil asam lemak yang berbeda. Perlakuan A3 dihasilkan SAFA tertinggi $(26,82 \%)$ diikuti oleh A1 $(24,58 \%)$ dan A2 (23,66\%) terendah. Komposisi asam lemak jenuh (SAFA) didominasi oleh asam lemak palmitat dan stearat. Kombinasi perlakuan A3 dihasilkan MUFA tertinggi dengan jumlah $(32,71 \%)$ dan terendah pada kombinasi A1 sebesar 27,21\%). Kadar asam lemak tak jenuh tunggal (MUFA) tertinggi asam oleat pada ketiga kombinasi perlakuan. Sampel A2 (1:2) kandungan PUFA tertinggi (32,53\%) dan terendah pada sampel A3 (2:1) $(28,10 \%)$. Kandungan EPA tertinggi terdapat pada sampel A3 $(0,13 \%)$ dan terendah A2 $(0,09 \%)$. Asam lemak tak jenuh ganda (PUFA), kandungan tertinggi adalah asam lemak linoleat. Kandungan DHA tertinggi sebesar
0,13 \% pada A3 dan terendah A2 (0,09\%). Menurut Swanson et al. (2012) peranan EPA dan DHA untuk perkembangan janin dan suplemen bagi ibu hamil. Hasil analisis profil asam lemak menunjukkan kombinasi perlakuan penambahan minyak hati ikan hiu dapat meningkatkan kandungan asam lemak omega 3 dan omega 6 pada minyak ikan patin. Pernyataan ini didukung oleh hasil penelitian Rozi et al. (2016) menunjukkan bahwa komposisi asam lemak minyak hati ikan hiu cucut pisang dihasilkan asam palmitat 12,59\%, asam oleat $17,86 \%$, EPA $1,50 \%$ dan DHA $14,35 \%$ dengan total SFA $18,59 \%$, total MUFA 24,54 dan total PUFA 19,11\%. Beberapa spesies ikan laut memiliki kandungan PUFA (4,11-99,63 mg/gr), MUFA (66,17-467,22 $\mathrm{mg} / \mathrm{g})$ dan SFA (13,11-486,55 mg/g) dengan konsentrasi asam lemak dominan yakni asam lemak oleat dan palmitat (Soeseno et al. 2010).

Kandungan asam lemak omega 3 dan omega 6 tertinggi terdapat pada kombinasi perlakuan A2 sebesar 2,56 \% dan 29,75\%. Kombinasi perlakuan A3 kandungan asam lemak omega 3 dan 6 dan terendah sebesar 29,75 dan 25,51\%. Penambahan minyak hati ikan hiu pada minyak ikan patin dapat meningkatkan kandungan asam lemak omega 3 dan omega 6. Asam lemak omega 3 dari ikan berperan dalam menurunkan kadar kolesterol darah, trigliserida dan memperbaiki kemampuan ekskresinya, memperbaiki fluiditas membran sel. Omega 6 bermanfaat mencegah pemecahan otot dan meningkatkan massa otot. Menurut Diana (2013) omega 3 dan omega 6 berperan untuk membantu melawan penyakit jantung dan depresi.

\section{KESIMPULAN}

Karakteristik kimia kombinasi minyak ikan patin dengan minyak hati ikan hiu A1 dan A3 asam lemak bebas memenuhi standar IFOS kecuali bilangan peroksida, iod, p-anisidin, penyabunan dan total oksidasi. Paramater mutu kimia minyak berdasarkan hasil analisis asam lemak bebas, bilangan peroksida, p-anisidin, dan nilai TOTOX merupakan parameter primer dan sekunder telah memenuhi standar mutu minyak berdasarkan IFOMA (1998). Komposisi asam lemak lemak kombinasi minyak hati ikan 
Table 2 Fatty acid composition of micture of catfish oil and shark liver oil

\begin{tabular}{|c|c|c|c|}
\hline \multirow{2}{*}{ Fatty acid composition } & \multicolumn{3}{|c|}{ Formulation } \\
\hline & A1 & A2 & A3 \\
\hline C12:0 (lauric) & 0.05 & 0.05 & 0.07 \\
\hline C14:0 (miristic) & 1.44 & 1.20 & 1.86 \\
\hline C15:0 (pentadecanoat) & 0.09 & 0.07 & 0.11 \\
\hline C16:0 (palmitate) & 18.40 & 18.24 & 20.01 \\
\hline C18:0 (stearic) & 3.88 & 3.59 & 4.26 \\
\hline C20:0 (aracidanate) & 0.27 & 0.24 & 0.26 \\
\hline C22:0 (behenic) & 0.32 & 0.16 & 0.12 \\
\hline C23:0 (tricosanoate) & 0.03 & 0.03 & 0.03 \\
\hline C24:0 (lignoseric) & 0.10 & 0.08 & 0.10 \\
\hline Saturated fatty acid (SAFA) & 24.58 & 23.66 & 26.82 \\
\hline C14:1 (myristoleat) & - & - & - \\
\hline C16:1 (palmitoleat) & 0.53 & 0,43 & 0.62 \\
\hline C17:1 (cis-10-heptadecanoat) & - & 0.05 & 0.06 \\
\hline C18:1 (oleic) & 30.34 & 29.45 & 32.01 \\
\hline C24:1 (nervonate) & 0.02 & 0.04 & 0.02 \\
\hline Monounsaturated fatty acid,MUFA & 30.89 & 29.97 & 32.71 \\
\hline C18:1 (elaidat) & 0.08 & 0.10 & 0.09 \\
\hline C18:2 (linoleic) ${ }^{* *}$ & 26.67 & 29.41 & 24.90 \\
\hline C18:3 (gamma-linolenic) ${ }^{\star *}$ & 0.16 & 0.12 & 0.30 \\
\hline C18:3 (linolenic)* & 2.02 & 2.30 & 1.62 \\
\hline C20:2 (eicosadienate) $)^{\star *}$ & 0.32 & 0.22 & 0.31 \\
\hline C20:4 (aracidonate) ${ }^{* *}$ & 0.16 & 0.12 & 0.20 \\
\hline C20:5n3 (eicosapentanoate)* & 0.11 & 0.09 & 0.13 \\
\hline C22:6n3 (docosaheksanoat)* & 0.19 & 0.17 & 0.25 \\
\hline Polyunsaturated fatty acid (PUFA) & 29.71 & 32.53 & 28.10 \\
\hline Saturated Fatty acid & 24.58 & 23.66 & 26.82 \\
\hline Unsaturated fatty acid & 60.60 & 62.50 & 60.81 \\
\hline Omega $3^{*}$ & 2.32 & 2.56 & 2.00 \\
\hline Omega $6^{* *}$ & 27.15 & 29.75 & 25.51 \\
\hline
\end{tabular}

hiu dengan ikan patin, patin (2:1), dihasilkan kandungan PUFA tertinggi sebesar 32,59\% yang didominasi oleh asam oleat. Kandungan asam lemak omega 3 dan omega 6 sebesar 2,59 dan $29,75 \%$.

\section{UCAPAN TERIMA KASIH}

Penelitian ini telah didanai Kemenristek BRIN Tahun Anggaran 2020 melalui Direktorat Riset Penelitian dan Pengabdian pada Skim Penelitian Dasar Penelitian Tesis Magister. 


\section{DAFTAR PUSTAKA}

Ahmad N. 2014. Analisis minyak hati ikan hiu botol (Centrophorus atromarginatus) di pantai Prigi Watulimo Trenggalek. Jurnal Agrina. 1(1):1-4.

[AOAC] Association of Official Analytical Chemists. 1995. Official Methods of Analysis. Maryland (US): Association of Official Analytical Chemists, Inc.

[AOAC] Association of Official Analytical Chemist. 2005. Official Method of Analysis of the Association of Official Analytical of Chemist. Arlington (US): The Association of Analytical Chemist, Inc.

[AOCS] American Oil Chemists Society. 1995. Official Methods and Recommended Practices of the American Oil Chemists' Society. Champaign (US): AOCS Press.

[AOCS] American Oil Chemists' Society. 2003. Official Methods and Recommended Practices of American Oil Chemists' Society. 5 th ed. Champaign. Illinois (US): AOCS

Bucher HC, Hengstler P, Schindler C, Meier G. 2002. N-3 polyunsaturated fatty acids in coronary heart disease: a meta-analysis of randomized controlled trial. The American Journal of Medicine. 112: 298304.

Diana FM. 2013. Omega-6. Jurnal Kesehatan Masyarakat. 7(1): 26-31.

Damongilala L. 2008. Kandungan asam lemak tak-jenuh minyak hati ikan cucut botol (Cenctrophorus sp.) yang diekstraksi dengan cara pemanasan. Jurnal Ilmiah Sains. 8(2): 249-253.

Harris WS, Mozaffarian D, Rimm E, Kris Etherton P, Rudel LL, Appel LJ. 2009. Omega 6 fatty acids and risk for cardiovascular disease: a science advisory from the American Heart Association Nutrition Subcommittee of the Council on Nutrition, Physical Activity, and Metabolism; Council on Cardiovascular Nursing; and Council on Epidemiology and Prevention American Heart Association. Circulation. 119(6): 902-907.
Haris W.S. 2004. Ulasan: Suplementasi minyak ikan: Bukti manfaat kesehatan. Jurnal Kedokteran, 71(3): 208-219

Hastarini E. 2012. Karakteristik minyak ikan dari limbah pengolahan filet ikan patin siam (Pangasius hypopthalmus) dan ikan patin jambal (Pangasius djambal). Jurnal Agritech. 32(4): 403-410.

[IFOS] International Fish Oil Standard. 2011. http//www.omegavia.com/ best-fishoilsupplement-3/. Diakses pada tanggal 12 September 2020.

[IFOMA] International Fishmeal and Oil Manufacurers Association. 1998. Guidelines for characterising food grade fish oil. 9(5): 473-483.

Jacobsen, C. 2004. Developing polyunsaturated fatty acids as functional ingredients. In: Functional foods, cardiovascular disease and diabetes. Arnoldi A (ed.). 2004. Boca Raton (US): CRC Press.

Ketaren S. 2005. Pengantar teknologi minyak dan lemak pangan. Jakarta (ID): UI Press

Kilcast D, Subramaniam Persist. 2011. Food and Beverage Stability and Shelf Life. Cambridge (GB): Woodhead Publishing.

Perrin JL. 1996. Determination of Alteration. In: Karleskind A, Wolff JP. (Eds.) Oils and Fats, Manual vol. 2. France (FR): Lavoisier Publishing

Rodiah NS, Utomo BSB, Basmal J, Hastarini E. 2016. Pemurnian minyak ikan patin dari hasil samping pengasapan ikan. Jurnal Kelautan dan Perikanan. 11(2): 171-182

Rozi A, Suseno SH, Jacoeb AM. 2016. Ekstraksi dan karakterisasi minyak hati cucut pisang. Jurnal Pengolahan Hasil Perikanan Indonesia. 19(2): 100-109.

Suseno SH, Yang TA, Nadia WA, Hamidah A, Ali S. 2010. Inventory and characterization of selected deep sea fish species as an alternative food source from Southern Java Ocean and Western Sumatra Ocean, Indonesia. International Journal of Biological, Biomolecular, Agricultural, Food and Biotechnological Engineering. 4(8): 651-654. 
Swanson D, Block R, Mousa SA. 2012.

Omega-3 Fatty Acids EPA and DHA:

Health Benefits Throughtout Life.

Advances in Nutrition. 3: 1-7.

Thammapat P, RaviyanP, Siriamornpun

S. 2010. Proximate and fatty acids composition of the muscles and viscera of Asian catfish (Pangasius bocourti). Food Chemistry. 122(1): 223-227.

Von Schack C. 2003. The role of omega-3 fatty acids in cardiovascular disease. Current Atherosclerosis Reports. 5: 139-145. 